\title{
Adverbial Middle Detachment Semantic Motivations and Detachment Rules in GRE Academic English
}

\author{
Wenjun Wang \\ Foreign Language School, Kunming University, \\ \#2 Puxin Road, Economy and Technology Development Zone, Kunming, Yunnan, China 650214 \\ wwj-201@163.com
}

\begin{abstract}
Adverbial middle detachment is thus called when the adverbial, usually occurring at the beginning or at the end of a clause in general English, is detached to the middle of the clause. Adverbial middle detachment contributes one of the remarkable divergences between general English and academic English. Those sociological discourses in GRE demonstrate this semantic phenomenon. From the standpoints of semantics and discourse analysis, adverbial middle detachment is in possession of clear semantic motivations. Instead of being self-willed, the word order of the adverbial in the middle detachment is governed by certain rules.
\end{abstract}

Key words: academic English; adverbial middle detachment; semantic motivations; detachment rules; GRE

The word order of adverbial in a clause is so flexible that it seems that an adverbial has several suitable locations. But the truth is that the word order of an adverbial is not self-willed, but subject to semantics in order to ensure the promotion of the theme, the clearness of the modification, the reasonable structure of the clause and the strictness of logics. Therefore, under many circumstances is never the word order of an adverbial unconditionally flexible. [1] Compared with general English, adverbial middle detachment is more likely to occur in academic English with certain semantic motivations and subject to certain detachment rules.

\section{A Literature Review on Adverbial Word Order and Its Semantic Motivations}

Dissel thinks the adverbial word order can be reasoned by syntactic analysis, syntactic identification habits, discourse pragmatic functions and semantic iconicity. [2] Quirk and Greenbaum think that adverbial clause of time usually appears in the foregrounding position, but they also admit that in some cases the when- clauses must be put at the end of a sentence [3] in order to express the dramatic or climax information. [4] Quirk finds two inner arrangements of a clause: end-focus and end-weight. [5] Just like Dissel, Haiman also explains the reason of word order (including adverbial) in a clause from the perspective of iconicity. He believes that language composition distance reflects the cognitive distance. [6] Chinese scholar Guowen Huang thinks that the position of adverbials in coherent discourse should consider not only the semantic focus and weight but also the discourse including reference, transition and cohesion. [1] Some scholars point out that, in dealing with the position of adverbials, theme should remain the same in order to maintain the topic of the discourse unchanged. [7] Some scholars, by studying the relationship between the adverbial and the words modified by it, sum up some rules. [8]

This paper, on the basis of the above study, by taking GRE social science academic English as corpus, focuses on the semantic motivations and rules of adverbial middle detachment. 


\section{The Semantic Motivations of Adverbial Middle Detachment in GRE Academic English}

Adverbial middle detachment refers to the phenomenon in which an adverbial is moved to the middle of a clause instead of being placed at its usual position, the beginning or the end of the clause. Through a careful search of corpus, 29 typical adverbial detachments are picked out from the 50 social science reading materials. Those 29 adverbial detachments possess obvious semantic motivations.

\subsection{Avoiding the change of theme to keep the smooth information flow}

If the middle-detached adverbial is placed at the beginning of a clause, the clause also makes sense and even sounds smoother, but when this is done, the theme will be changed, and the topic together with the smooth flow of the information will be derogated. It is because of the high requirements of academic English on coherence and cohesion, the adverbial has to be detached.

Example: Garrison government allowed the colonists a legislative assembly, but real authority, in Webb's view, belonged to the colonial governor, who was appointed by the king and supported by the garrison.

The adverbial "in Webb's view" could be placed after "but" and before "real authority", but when this happened, "in Webb's view" would take the place of "real authority" to be the new theme of the second half. The coherence will be derogated and the information will be choppy.

\subsection{Promoting the semantics of an adverbial}

For the adverbial semantic problem, Quirk thinks that the middle-detached position in a clause is "weird". [9] Only for a particular effect will a comparatively long prepositional phrase be middle detached, and then in the written language commonly comma will be used before and after the adverbial to separate it from other ingredients clearly. [10] It is this "weird" that will catch the readers' attention, and thus create a special effect and promote the adverbial semantics. By doing so, the academic English could convey more semantics with fewer words. [11]

Example: If from the outset Black people were discriminated against, the legal slavery should be viewed as a reflection and an extension of racial prejudice rather than, as many historians including the Hanlins have argued, the cause of prejudice.

This discourse out of which this clause is picked intents to comment on Hanlins' researches on American slavery origin. The italic adverbial could be right moved to the end of the clause. But the next clause begins with "In addition, the existence of discrimination before the advent of legal slavery offers a further explanation for the harsher treatment of Black slaves in North than in South America." The left detachment of the adverbial will destruct the cohesion of "prejudice" and "discrimination". In addition, undoubtedly, "Hanlins" is the semantic focus of this discourse; therefore by middle detaching this adverbial, "Hanlins" is promoted.

\subsection{Not disturbing end-focus and end-weight}

As discussed above, end-focus and end-weight are two cognitive rules in arranging a clause. These two rules naturally lead a writer to put the focus and weight at the end of a clause, thus, an adverbial which sounds well when put at the end would have to be middle detached in spite of being "weird".

Example: With regard to this last question, we might note in passing that Thompson, while rightly restoring laboring people to the stage of eighteenth-century English history, has probably exaggerated the opposition of these people to the inroads of capitalist consumerism in general.

The discourse out of which this clause is picked comments on historians' researches on the $18^{\text {th }}$ 
century British consumption needs. It is obvious that "consumerism", rather than this italic adverbial, is the focus, therefore, the best policy is to middle detach the italic adverbial instead of putting it at the end of the clause, besides, by doing so, the " $18^{\text {th }}$ century" is promoted.

\section{Adverbial Middle Detachment Rules}

Adverbial middle detached is somewhat confusing for "middle" can not suggest an exact place in a clause. By researching the corpus, some rules about middle detachment emerge.

\subsection{Middle detachment should not disturb the recognition domain}

Hawkins uses "recognition domain" to refer to a semantic structure. [12] For example, the following clause contains 5 recognition domains: "I / introduced / some friends / that John had brought to the party / to Mary." He thinks that the quick and easy identification of a recognition domain will promote the understanding effectiveness and efficiency. [13] The corpus shows that, when an adverbial middle detached, the recognition domain is always well protected.

Example: (1) Pessen does present a quantity of examples, together with some refreshingly intelligible statistics, to establish the existence of an inordinately wealthy class.

The italic adverbial is middle detached between the first and the last recognition domain.

\subsection{Middle detached adverbial should be put close to the word(s) it governs}

To avoid ambiguity, an adverbial when middle detached should get close to the word(s) it governs. The following are the regular adverbial middle detachment position:

(1) Before the verb(s) it governs.

Example: Its acquisition by the adolescent, in even the most modest sense, requires the acquisition of relatively sophisticated cognitive skills.

(2) After the pronominal anaphora.

Example: Despite the existence of excellent narrative accounts, the February Days, as this revolt is called, have been largely ignored by social historians of the past two decades.

(3) Between link verb and predictive;

Example: The contradiction inherent in this situation was, for many, a source of constant embarrassment.

(4) so + adj. + middle-detached adverbial + that

Example: Islamic law is a phenomenon so different from all other forms of law ---notwithstanding, of course, a considerable and inevitable number of coincidences with one or the other of them as far as subject matter and positive enactments are concerned --- that its study is indispensable in order to appreciate adequately the full range of possible legal phenomena.

(5) When contradiction happens, iconicity will be applied.

Example: In any case, the field of human relations, with its vast literary documentation but meager scientific treatment, is in great contrast to the field of physics in which there are relatively few nonscientific books.

In this clause, the italic adverbial has a pronominal anaphora "its". So it is closer to "the field of human relations" in iconicity than to "is in great contrast", therefore, it is put exactly after "the field of human relations" rather than between the link verb and predictive.

\section{Conclusions}

From the research of the corpus the GRE 50 reading materials, it is safe to draw the conclusion that the adverbial middle detachment clauses in GRE social science discourses possess 
apparent semantic motivations and the middle detachment is not self-willed but does follow certain rules. The deficiency of this paper is that the conclusions are not very well supported by the presently collected adverbial middle detachment clauses. More corpuses should be collected and researched in order to explore the deep cognitive truth of adverbial middle detachment.

\section{References}

[1] Huang, Guowen. The Position of English Adverbial Clause [J]. Modern Foreign Language, 1984(1): 24-30

[2] Dissel, H. Competing Motivations for the Ordering of Main and Adverbial Clauses [J]. Linguistics, 2005(43): 449-70

[3] Quirk, R., Sidney Greenbaum. A University Grammar of English [M]. London: Longman Group Limited, 1973:323

[4] Quirk, R. et al. A Comprehensive Grammar of the Language [M]. London: Longman World Publishing Corp., 1985: 1084

[5] Quirk, R., Sidney Greenbaum. A University Grammar of English [M]. London: Longman Group Limited, 1974: 410

[6] Haiman, John. Iconic and Economic Motivation[J]. Language, 1983(59): 781-819.

[7] Chen, Chunhua. The Influence of the Distributional Differences in Chinese and English Time Clauses on ESL Students' Writing [J]. Journal of PLA University of Foreign Languages, 2004(1):75-78

[8] Wang, Xiaowei. The Semantic Constraints and Textual Function of Clause-initial Temporal Adjuncts in English [J]. Journal of University of Science and Technology Beijing (Social Sciences Edition), 2015:26-34

[9] Fang, Zhenghui, Ding Yuzao. A Functionalist Analysis of Relative Clause Extraposition Constructions in English [J]. Joumal of Yichun College, 2012: 119-123

[10] Quirk, R., Greenbaum, S., Leech, G. \& Svartvik, J. A Comprehensive Grammar of the English Language [M]. Shanghai: East China Normal University Press, 1989: 672

[11] Wu, Zhongdong, Wu, Xinxiang. GRE Read Comprehension Breakthrough: Senior Reading Course [M]. Beijing: Yuhang Press, 1998:1

[12] Hawkins, J. A.. A Parsing Theory of Word Order Universals [J]. Linguistic Inquiry, 1990(21): 223-261

[13] Hawkins, J. A.. A Performance Theory of Order and Constituency [M]. Cambridge: CUP, 1994:259 